\title{
ASPECTOS FISIOLÓGICOS DA GERMINAÇÃO E DA QUALIDADE DE PLÂNTULAS DE Schizolobium amazonicum EM RESPOSTA À ESCARIFICAÇÃO DAS SEMENTES EM LIXA E ÁGUA QUENTE ${ }^{1}$
}

\author{
Elizabeth Santos Cordeiro Shimizu², Hugo Alves Pinheiro ${ }^{3}$, Marcelle Auday Costa ${ }^{4}$ e \\ Benedito Gomes dos Santos Filho ${ }^{4}$
}

\begin{abstract}
RESUMO - Sementes de Schizolobium amazonicum apresentam dormência física a qual pode ser quebrada por diferentes métodos de escarificação. Nesta pesquisa, os efeitos da escarificação das sementes em lixa e água quente sob os aspectos fisiológicos relacionados à germinação das sementes e à qualidade das plântulas obtidas foram avaliados. Sementes de S. amazonicum foram escarificadas pela (i) imersão em água a $100^{\circ} \mathrm{C} /$ 2 min e pela (ii) friç̧ão das sementes em lixa. Sementes não escarificadas foram utilizadas como testemunha. As seguintes variáveis foram avaliadas: viabilidade dos tecidos (por meio do teste de tetrazólio), taxa de germinação, índice de velocidade de germinação (IVG), taxa de embebição das sementes, depleção do endosperma e emergência, uniformidade e acúmulo de biomassa das plântulas resultantes. As sementes oriundas de ambos os tratamentos foram igualmente coradas pelo tetrazólio. A escarificação em lixa resultou em maior germinação, maior IVG, rápida embebição e depleção do endosperma em comparação às sementes escarificadas em água a $100^{\circ} \mathrm{C} / 2 \mathrm{~min}$. A emergência de plântulas e o índice de emergência foram maiores em sementes escarificadas em lixa, cujas plântulas apresentaram-se mais uniformes e com maior acúmulo de biomassa que aquelas obtidas após escarificação em água a $100^{\circ} \mathrm{C} / 2 \mathrm{~min}$. Do exposto, a escarificação de sementes de paricá em lixa é mais eficiente na promoção da germinação e produção de plântulas uniformes.
\end{abstract}

Palavras-chave: Dormência física, Embebição e Endosperma.

\section{PHYSIOLOGICAL ASPECTS OF GERMINATION AND SEEDLING QUALITY OF Schizolobium amazonicum IN RESPONSE TO SANDPAPER AND HOT WATER SEED SCARIFICATION}

\begin{abstract}
Seeds of Schizolobium amazonicum present physical dormancy which can be broken through different scarification methods. In this work, the effects of sandpaper and hot water seed scarification on physiological aspects related to seed germination and seedling quality were evaluated. Seeds of S. amazonicum were scarified by (i) immersion in water at $100^{\circ} \mathrm{C} / 2$ min and (ii) by scrubbing seeds on sandpaper. Nonscarified seeds were used as control. The following variables were evaluated: tissue viability (by using tetrazolium test), germination rate, speed germination index (SGI), seed imbibition rate, endosperm depletion, and seedling emergence rate, uniformity and biomass accumulation. Seeds from both treatments were equally dyed by tetrazolium. Seeds scarified on sandpaper showed higher germination rate, higher SGI, faster seed imbibition and endosperm depletion than those scarified in water at $100^{\circ} \mathrm{C} / 2 \mathrm{~min}$. Seeds scarified on sandpaper presented higher seedling emergence rate and emergence index, and their seedlings were more uniform and with greater biomass than those obtained after scarification in water at $100^{\circ} \mathrm{C} / 2 \mathrm{~min}$. Therefore, scarification of paricá seeds on sandpaper is more efficient in promoting germination and production of uniform seedlings.
\end{abstract}

Keywords: Endosperm, Imbibition and Physical dormancy.

\footnotetext{
${ }^{1}$ Recebido para publicação em 25.09.2009 e aceito para publicação em 20.04.2011.

${ }^{2}$ Laboratório de Sementes Florestais, Embrapa Amazônia Oriental, Brasil. E-mail:<beth@cpatu.embrapa.br>.

${ }^{3}$ Instituto Sócio-Ambiental e dos Recursos Humanos, Universidade Federal Rural da Amazônia, UFRA, Brasil. E-mail: <hugo.pinheiro@ufra.edu.br>.

${ }^{4}$ Instituto de Ciências Agrárias, Universidade Federal Rural da Amazônia, UFRA, Brasil. E-mail: <benedito.santos@pesquisador.cnpq.br>.
} 


\section{INTRODUÇÃO}

O paricá [Schizolobium parahyba var. amazonicum (Huber ex Ducke) Barneby] é uma espécie florestal pertencente à família Fabaceae (Leguminosae), subfamília Caesalpinoideae (BARNEBY, 1996) e popularmente conhecido como guapuruvu, bageiro, fava divina, dentre outros. Ocorre na Amazônia em florestas primárias e secundárias de terra firme e várzea alta, principalmente no Amazonas e no Pará (MARQUES et al., 2004). Sua madeira é leve e de processamento fácil, comumente utilizada na fabricação de palitos de fósforo, saltos de calçados, brinquedos, maquetes, embalagens leves, etc. (FALESI; SANTOS, 1996; ROSA; PINHEIRO, 2001). Dados sua importância econômica e seu rápido crescimento, o paricá tem sido recomendado para a formação de plantios comerciais e, por essa razão, a demanda por mudas uniformes e de qualidade tem aumentado consideravelmente.

Apesar de muitos protocolos de propagação de paricá por meio de cultura de tecidos e segmentos caulinares (estacas) terem sido desenvolvidos nos últimos anos (ROSA; PINHEIRO, 2001; CORDEIRO et al., 2007; REIS et al., 2008), a produção de mudas é geralmente realizada via seminífera. No entanto, quando as sementes de paricá são semeadas sem que nenhum método de escarificação tenha sido aplicado, a germinação ocorre lentamente e a taxas reduzidas (MARUYAMA; UGAMOTO, 1989). Para obtenção de uma taxa de germinação superior a 90\%, um tempo prolongado, de aproximadamente 2.310 dias, seria necessário (CRUZ; CARVALHO, 2006). Portanto, o longo tempo requerido para a obtenção de alta taxa de germinação sem aplicação de métodos de escarificação é uma forte evidência de que as sementes de paricá são acometidas por uma dormência física ou tegumentar capaz de limitar a rápida e uniforme germinação das sementes (BASKIN; BASKIN, 1998; CRUZ et al., 2001). Isto é um problema à obtenção de mudas uniformes e em qualidade para atender as demandas de mercado.

De acordo com Fowler e Bianchetti (2000), a dormência física de sementes pode ser quebrada pela utilização de ácido sulfúrico $\left(\mathrm{H}_{2} \mathrm{SO}_{4}\right)$. Em paricá, uma taxa de germinação de $92 \%$ foi obtida após a incubação das sementes em $\mathrm{H}_{2} \mathrm{SO}_{4}$ concentrado por $60 \mathrm{~min}$ (CRUZ et al., 2007). No entanto, o uso de ácido sulfúrico é insalubre e, por isso, não recomendado ao produtor. Alternativamente, a imersão em água quente pode ser utilizada e, nesse caso, as temperaturas entre 60 e $100^{\circ} \mathrm{C}$ são comumente empregadas. A imersão em água a $80^{\circ} \mathrm{C}$, seguida da imersão em água na temperatura ambiente por $18 \mathrm{~h}$, foi um eficiente método para promover altas taxas de germinação em Acacia longifolia (MEDEIROS; ZANON, 1999) e Mimosa bimucronata (FOWLER; CARPANEZZI, 1998). A imersão de sementes de Schizolobium amazonicum em água a $80^{\circ} \mathrm{C}$ e a $100^{\circ} \mathrm{C}$, por 2 min, seguida de embebição em água por $24 \mathrm{~h}$ (temperatura ambiente), resultou em 19,5 e 39,5\% de germinação, respectivamente, após 12 dias do semeio. Esses valores podem chegar a 91,5\% após a escarificação das sementes em lixa, seguida de embebição em água destilada em temperatura ambiente por 24 h (CRUZ; CARVALHO, 2006). Esses resultados sugerem claramente que a escarificação das sementes em lixa e em água quente apresentam diferentes eficiências na quebra da dormência tegumentar de paricá. Com efeito, esses métodos de escarificação devem influenciar diferentemente o estabelecimento de plântulas e mudas.

Assim, o objetivo geral deste trabalho foi avaliar as alterações fisiológicas relacionadas à germinação e à qualidade de plântulas de Schizolobium amazonicum em função da escarificação das sementes em lixa e em água quente. Como objetivos específicos, foram avaliados os efeitos dos métodos de escarificação na (i) germinação, (ii) embebição, (iii) viabilidade dos tecidos, (iv) depleção do endosperma, (v) emergência, (vi) uniformidade e no (vii) acúmulo de biomassa nas plântulas resultantes.

\section{MATERIAL E MÉTODOS}

Sementes de paricá (Schizolobium parahyba var. amazonicum (Huber ex Ducke) Barneby) foram coletadas na reserva indígena Parakanã, Tucuruí (0346'04'”S, 4940’22”'O), sudeste do estado do Pará, Brasil. As sementes foram armazenadas em câmara úmida, a $15^{\circ} \mathrm{C}$, no Laboratório de Análise de Sementes Florestais (Embrapa Amazônia Oriental, Belém-PA), até a instalação do experimento no Laboratório de Físico-química (Centro de Tecnologia Agropecuária - ISARH, Universidade Federal Rural da Amazônia, Belém-PA). Antes dos experimentos definitivos, foi realizada a triagem das sementes visando descartar aquelas imaturas e deterioradas e as que apresentavam danos tegumentares. As sementes foram imersas em hipoclorito de sódio a 2\%, por 1 min, e lavadas em água destilada para remoção dessa solução. Após secagem em papel absorvente, 
as sementes foram utilizadas imediatamente nos diversos testes de interesse. O experimento foi instalado em delineamento inteiramente casualizado, consistindo de três tratamentos: (i) sementes sem escarificação (Controle), (ii) sementes escarificadas por imersão em água destilada a $100^{\circ} \mathrm{C}$, por 2 min e (iii) sementes escarificadas por fricção em lixa de madeira (número 180), na região oposta ao eixo embrionário.

Para o teste de germinação, as sementes foram embebidas em água destilada por $24 \mathrm{~h}$ (a $25^{\circ} \mathrm{C}$ ) e, em seguida, dispostas em rolos de papel "germitest", umedecidos com água destilada, no volume de 3 vezes o peso do papel (RAMOS et al., 2006). As sementes foram incubadas em câmara de germinação (TE401, Tecnal, São Paulo, Brasil) a $25^{\circ} \mathrm{C}$ e fotoperíodo de $12 \mathrm{~h}$. Foram utilizadas quatro repetições de 25 sementes por tratamento, sendo consideradas germinadas as sementes cuja radícula apresentasse pelo menos $1 \mathrm{~cm}$ de comprimento. O teste de germinação foi conduzido pelo tempo necessário para a uniformização (estabilização) da germinação em pelo menos um dos tratamentos. Os resultados foram expressos em percentagem de geminação. O índice de velocidade de germinação (IVG) foi determinado por contagens diárias das sementes germinadas, conforme descrito nas RAS (BRASIL, 1992).

Para a determinação da curva de embebição as sementes de paricá (controle e escarificadas) foram pesadas para a obtenção de seu peso inicial $\left(\mathrm{P}_{\mathrm{i}}\right)$. Em seguida, foram imersas em água destilada, a $25^{\circ} \mathrm{C}$, na proporção de 25 sementes para cada $400 \mathrm{~mL}$ de água destilada. A cada $12 \mathrm{~h}$ subseqüentes, as sementes foram secas em papel absorvente e novamente pesadas (pesos temporais, $\mathrm{P}_{\mathrm{t}}$ ). O teste foi realizado por um tempo total de 72 h e a embebição $(E)$ a cada tempo calculada de acordo com a equação $E=\left(\left(\mathrm{P}_{\mathrm{t}}-\mathrm{P}_{\mathrm{i}}\right) / \mathrm{P}_{\mathrm{i}}\right) \times 100$. Os resultados foram expressos em percentagem.

A viabilidade dos tecidos foi averiguada pelo teste de tetrazólio. Sementes de paricá foram incubadas em água destilada a $25^{\circ} \mathrm{C}$, por $24 \mathrm{~h}$, e, em seguida, separadas em tegumento, endosperma e eixo embrionário + cotilédones. Cada parte da semente foi imersa em solução de cloreto de 2,3,5-trifenil-tetrazólio a 0,075\% (pH 6,5), à $25^{\circ} \mathrm{C}$, na ausência completa de luz, por $3 \mathrm{~h}$ (SHIMIZU et al., 2008). A solução de tetrazólio foi removida por lavagem em água destilada. Foram consideradas viáveis as sementes que apresentaram coloração vermelha uniformemente distribuída nas estruturas das sementes
(DELOUCHE et al., 1976; BRASIL, 1992). Neste teste, foram utilizadas quatro repetições de 25 sementes por tratamento.

O consumo de reservas do endosperma (depleção do endosperma) foi avaliado por meio das variações nos seus pesos enquanto frescos e secos durante a germinação. Neste ensaio, sementes de paricá (embebidas em água destilada a $25^{\circ} \mathrm{C}$, por $24 \mathrm{~h}$ ) foram incubadas em câmara de germinação como descrito para o teste de germinação. A cada dois dias (de um total de doze dias), amostras de sementes foram coletadas, abertas, e o endosperma remanescente extraído com auxílio de uma espátula. O peso enquanto fresco foi obtido, e as amostras submetidas à secagem em estufa com circulação de ar, a $65^{\circ} \mathrm{C}$, até massa constante, para a determinação de seu peso enquanto seco. Os resultados foram expressos em grama de matéria fresca ou seca.

A emergência, a uniformidade e o acúmulo de biomassa pelas plântulas foram averiguados em casa de vegetação por um período de 24 dias. As sementes correspondentes a cada um dos tratamentos (sanitizadas e embebidas) foram semeadas em bandejas de polietileno, preenchidas com $3 \mathrm{~kg}$ de areia lavada e esterilizada em autoclave $\left(120^{\circ} \mathrm{C}, 15 \mathrm{~min}\right)$. As médias de temperatura e umidade relativa diurnas do ar foram de $30^{\circ} \mathrm{C}$ e $85 \%$, respectivamente, enquanto a média diurna de radiação incidente ao meio dia foi de $700 \mathrm{mmol} \mathrm{m}^{-2} \mathrm{~s}^{-1}$. A umidade do substrato foi mantida pela adição diária de $200 \mathrm{~mL}$ de água destilada em cada bandeja. A percentagem de emergência e o Índice de Velocidade de Emergência (IVE) foram determinados de acordo com Maguire (1962). Foram utilizadas quatro repetições por tratamento, constituídas de 25 sementes cada uma. A uniformidade de emergência das plântulas foi verificada classificandose os indivíduos de cada bandeja (repetição) nas seguintes classes: plântulas completas (PC; presença de radícula e raízes, hipocótilo, epicótilo, folhas jovens, com ou sem cotilédones), plântulas incompletas (PIC, presença de radícula e raízes, hipocótilo, cotilédones, com ou sem tegumento), sementes germinadas (SG, radícula aparente e demais partes da semente envoltas pelo tegumento), sementes mortas (SM; sementes não germinadas e com tecidos visivelmente deteriorados) e sementes não germinadas ( $S N G$, sementes não germinadas e com tecidos vivos). A frequência relativa de cada classe foi obtida por contagem direta do número de indivíduos dentro de cada classe em relação ao total de sementes por bandeja (25 sementes). Os dados foram 
expressos em percentagem. Em seguida, as plântulas foram separadas de acordo com as estruturas (folhas, hipocótilo, epicótilo, cotilédone, raízes e radícula), e estas foram secas em estufa com circulação forçada de ar, a $65^{\circ} \mathrm{C}$, até massa constante, para a obtenção de seus pesos enquanto secas.

As análises estatísticas levaram em conta o delineamento inteiramente casualizado. Os dados de percentagem de germinação e depleção do endosperma foram submetidos à análise de variância, e as médias dos tratamentos comparadas dentro de cada dia de avaliação pelo teste t-Student $(P<0,05)$. Apenas os dados de germinação e emergência foram transformados para arco seno $(\mathrm{x} / 100)^{0,5}$, embora os dados puros (em percentagem) tenham sido apresentados nos gráficos. Para as curvas de embebição, os dados foram submetidos à análise de variância e aplicados à regressão linear, cujas significâncias das equações foram averiguadas pelo teste $\mathrm{F}(P<0,05)$. Os dados de emergência, IE, frequência relativa de estruturas pós-germinativas e alocação de biomassa foram submetidos à análise de variância, e as médias entre tratamentos de escarificação comparadas pelo teste de Newman-Keuls $(P<0,05)$.

\section{RESULTADOS}

A percentagem de germinação variou significativamente entre os tratamentos de escarificação e em função do tempo de germinação (Figura 1A). Nas sementes escarificadas em lixa, a germinação iniciou-se a partir do $2^{\circ}$ dia, e o pico máximo ocorreu no $8^{\circ}$ dia (94\%), a partir do qual nenhum incremento significativo na germinação foi observado, indicando a estabilização do processo (Figura 1A). As sementes escarificadas em água a $100^{\circ} \mathrm{C} / 2 \mathrm{~min}$ apresentaram germinação lenta, iniciada no $8^{\circ}$ dia, e a máxima germinação (20\%) ocorreu no $12^{\circ}$ dia de ensaio (Figura $1 \mathrm{~A}$ ). Nas sementes escarificadas em lixa, o IG foi de 4,0 $\pm 0,77$ no $8^{\circ}$ dia (Figura $1 B$ ), enquanto este índice para as sementes escarificadas em água $100^{\circ} \mathrm{C} / 2 \mathrm{~min}$ foi de apenas $0,49 \pm 0,23$. As sementes não escarificadas (controle) não germinaram no período de 12 dias e, por essa razão, o IVG foi nulo (Figura 1A e 1B).

Nas sementes escarificadas em lixa ou em água $100^{\circ} \mathrm{C} / 2 \mathrm{~min}$, uma coloração vermelha e uniformemente distribuída foi observada no endosperma e eixo embrionário (Figura 2), cujos tecidos apresentaram-se firmes e sem danos aparentes. Uma pequena diferença
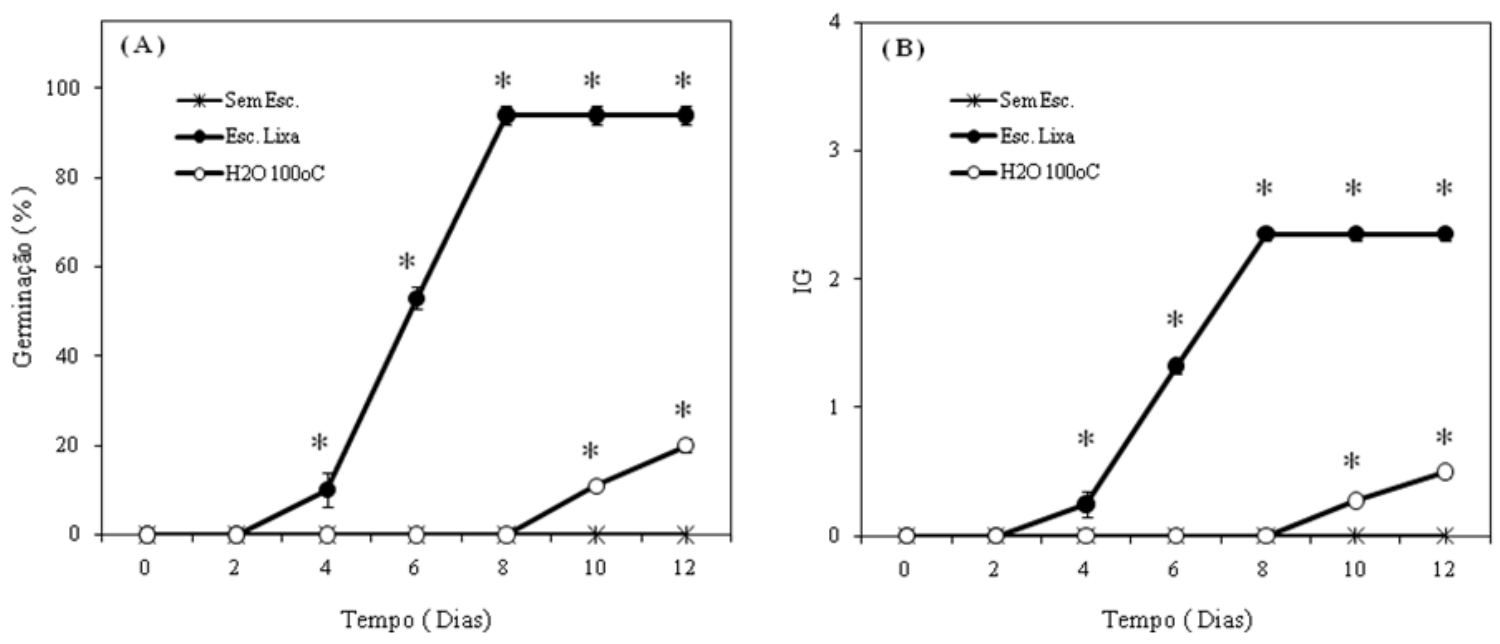

Figura 1 - Germinação (A) e índice de velocidade de germinação (IVG; B) de sementes de S. amazonicum após escarificação em lixa (Esc. Lixa) e em água quente (Esc. $\mathrm{H}_{2} \mathrm{O} 100^{\circ} \mathrm{C}$ ). Asteriscos indicam diferença significativa entre médias do tratamento de escarificação (lixa ou água quente) e o controle (sementes não escarificadas, Sem Esc.) quando comparados no mesmo tempo (teste $\mathrm{t}-$ Student, $P<0,05$ ). Os dados representam a média de quatro repetições \pm erro padrão (EP).

Figure 1 - Germination (A) and speed germination index (SGI; B) of S. amazonicum seeds after scarification on sandpaper (Scf. sandpaper) and hot water $\left(\mathrm{Scf} . \mathrm{H}_{2} \mathrm{O} 100^{\circ} \mathrm{C}\right)$. Asterisks denote significant differences between mean of scarification (sandpaper or hot water) and control (non scarified seeds, Sem Esc.) treatments compared at the same time (Student $t$-test, $P<0.05)$. Data are the mean of four replicates \pm standard error (SE).

Revista Árvore, Viçosa-MG, v.35, n.4, p.791-800, 2011 
de coloração foi observada nos cotilédones, de forma que as sementes escarificadas em água $100^{\circ} \mathrm{C} / 2 \mathrm{~min}$ apresentaram ausência de coloração vermelha em algumas regiões da borda cotiledonar. Em todo caso, mais de $75 \%$ das estruturas das sementes de ambos os tratamentos reagiram positivamente ao tetrazólio (Figura 2).

Nas sementes não escarificadas, os valores médios de embebição foram praticamente constantes ao longo do período de 72 h, com médias próximas de zero (Figura 3). Portanto, independente do tempo de embebição, as sementes não escarificadas não absorveram quantidades consideráveis de água (Figura 3). Para as sementes escarificadas em lixa, a embebição foi significativa após $12 \mathrm{~h}$ da imersão, com incrementos rápidos e significativos em cada tempo de avaliação e estabilização aparente após 72 h do tempo inicial. Nesse caso, as sementes absorveram um volume de água correspondente a aproximadamente $200 \%$ de seu peso inicial (Figura 3). Nas sementes escarificadas em água $100^{\circ} \mathrm{C} / 2 \mathrm{~min}$, a embebição iniciou-se 24 h após o início do teste; porém nessas sementes foi lenta e, no final do período experimental (72 h), não houve estabilização do processo (Figura 3).
As variações nas massas frescas e secas do endosperma sugerem diferentes padrões de mobilização de reservas em função da escarificação, e tais diferenças foram significativas a partir do segundo dia de avaliação (Figura 4). Para sementes escarificadas em água $100^{\circ} \mathrm{C} / 2 \mathrm{~min}$, o peso delas frescas variou de $3,48 \mathrm{~g}$ (dia 0) para 2,72 g (dia 12), e o peso das sementes secas de 1,42 (dia 0) para 1,06 g (dia 12), representando uma depleção do endosperma de aproximadamente 22 e $27 \%$, respectivamente, em relação ao tempo inicial (Figura 4A e 4B). Nas sementes escarificadas em lixa, o peso das frescas variou de $3,8 \mathrm{~g}$ (dia 0 ) para $0 \mathrm{~g}$ (dia 10) e de $1,48 \mathrm{~g}$ (dia 0 ) par $0 \mathrm{~g}$ (dia 10), indicando que o endosperma foi completamente exaurido durante a germinação (Figura 4A e 4B). Este teste não foi realizado com sementes não escarificadas porque não germinaram no período de 12 dias e nem apresentaram embebição.

Quando as sementes escarificadas em lixa ou em água quente foram semeadas em areia lavada (em casa de vegetação), foi observado que, após 24 dias do semeio, a escarificação em lixa promoveu maior emergência $(\mathrm{E}=97 \%)$ e IVE $(4,36)$ que para aquelas escarificadas em água a $100^{\circ} \mathrm{C} / 2 \mathrm{~min}(\mathrm{E}=62 \%$ e IVE $=1,60)$ (Tabela 1$)$.

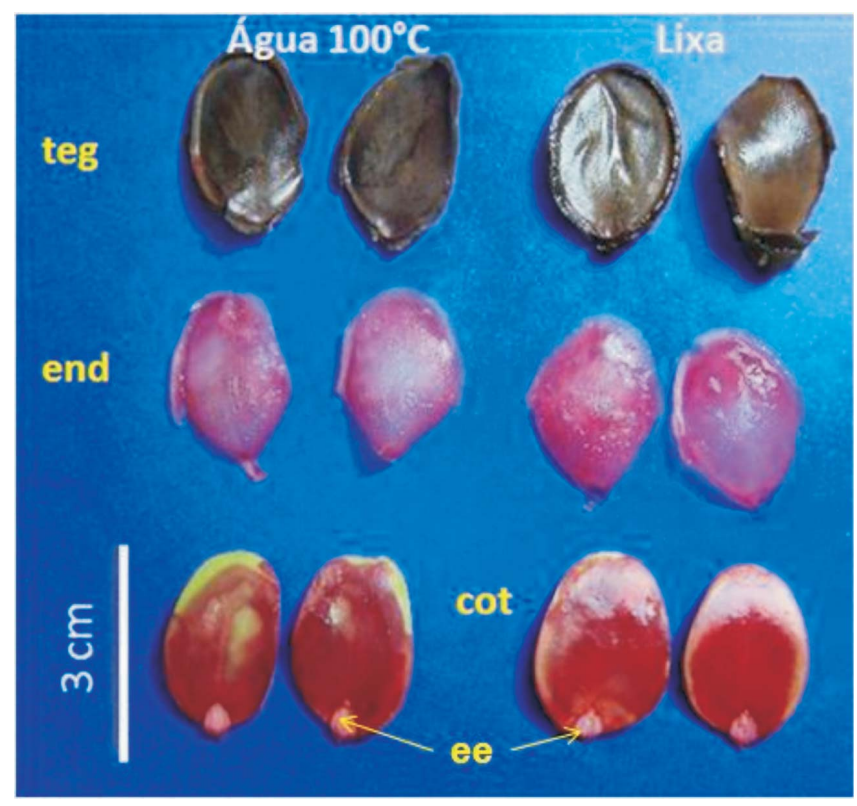

Figura 2 - Teste do tetrazólio em sementes de S. amazonicum após escarificação em lixa (Lixa) e em água quente (Água $100^{\circ} \mathrm{C}$ ). As imagens são representativas de quatro repetições e as abreviações referem-se a tegumento (teg), endosperma (end), cotilédones (cot) e eixo embrionário (ee).

Figure 2 - Tetrazolium test in S. amazonicum seeds after sandpaper scarification (Esc. Lixa) and hot water (Água $100^{\circ} \mathrm{C}$ ). Images represents four replicates and abbreviations refer to tegument (teg), endosperm (end), cotyledons (cot) and embryo axis (ee). 


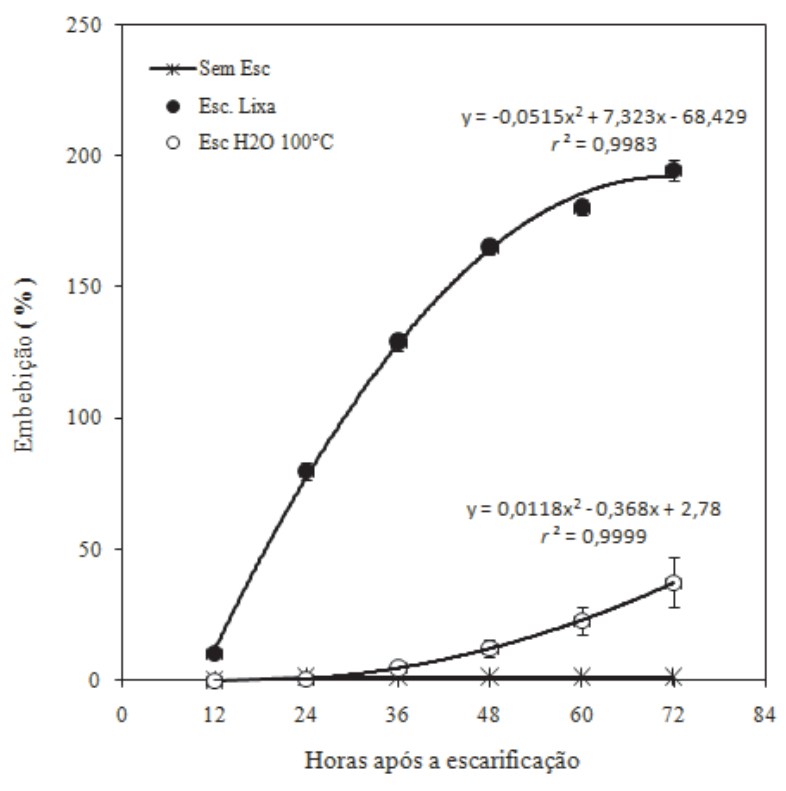

Figura 3 - Curvas de embebição de sementes de S. amazonicum após escarificação em lixa (Esc. Lixa) e em água quente (Esc. $\mathrm{H}_{2} \mathrm{O} 100^{\circ} \mathrm{C}$ ). Sementes não escarificadas (Sem Esc) foram usadas como controle. Os dados representam a média de quatro repetições \pm EP.

Figure 3 - Imbibition curves of S. amazonicum seeds after sandpaper scarification (Sandpaper scf.) and hot water (water $100^{\circ} \mathrm{C}$ ). Non-scarified seeds (No scf) were used as control. Data are the mean of four replicates $\pm S E$.

Quantitativamente, 83\% das plântulas emergidas após escarificação em lixa foram consideradas PC e 14\% foram consideradas PI. Não foram encontradas SG e SNG, mas as SM totalizaram 3\% (Tabela 1). Quanto às plântulas obtidas após a escarificação em água a $100^{\circ} \mathrm{C} / 2 \mathrm{~min}$, $35 \%$ foram consideradas PC e 19\% PI. Do restante das sementes, 8\% ainda se encontravam em germinação, 15\% não germinaram (possivelmente dormentes) e 23\% apresentaram necrose tecidual (sementes mortas). A biomassa acumulada diferiu entre tratamentos (Tabela 1), de forma que os maiores acúmulos de massa seca de folhas (60\%), epicótilo (76\%), hipocótilo (71\%) e raízes (67\%) foram observados em plântulas obtidas de sementes escarificadas em lixa em relação àquelas escarificadas em água $100^{\circ} \mathrm{C} / 2 \mathrm{~min}$.

\section{DISCUSSÃO}

Os resultados obtidos para taxa de germinação das sementes escarificadas em lixa ou em água $100^{\circ} \mathrm{C} /$ 2 min foram similares àqueles encontrados previamente

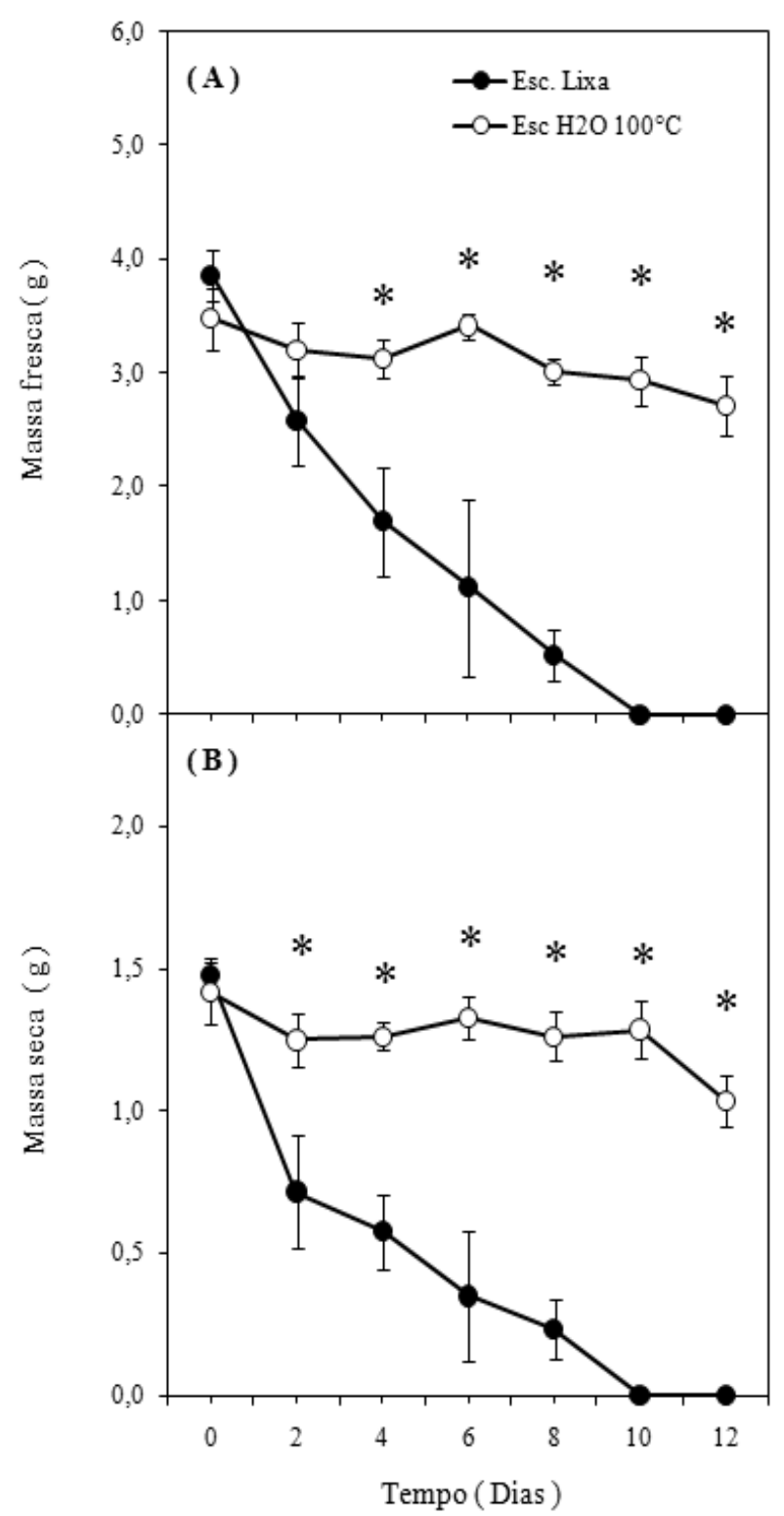

Figura 4-Variações na massa fresca (A) e seca (B) do endosperma durante a germinação de sementes de $S$. amazonicum escarificadas em lixa (Esc. Lixa) e em água quente (Esc. $\mathrm{H}_{2} \mathrm{O} 100^{\circ} \mathrm{C}$ ). Asteriscos denotam diferenças significativas entre tratamentos comparados no mesmo tempo (teste t-Student, $P<0,05$ ).

Figure 4-Changes in endosperm fresh (A) and dry (B) matter during germination of $\boldsymbol{S}$. amazonicum seeds sandpaper scarified (Sandpaper scf.) and hot water $\left(\mathrm{H}_{2} \mathrm{O} 100^{\circ} \mathrm{C} \mathrm{scf}\right)$. Asterisks denote significant differences among treatments compared at the same time (Student t-test, $P<0.05$ ). 
Tabela 1 - Indicativos de vigor (Emergência, E; e índice de velocidade de emergência, IVE), uniformidade de emergência (plântulas completas, PC; plântulas incompletas, PI; sementes germinadas, SG; sementes não germinadas, SNG; e sementes mortas, SM) e acúmulo de biomassa em plântulas de S. amazonicum.

Table 1 - Indicatives of vigor (Emergence, E; and speed emergence index, SEI), emergence uniformity (complete seedlings, CS; incomplete seedlings, IS; germinated seeds, GS; non-germinated seeds, NGS; and dead seeds, DS) and biomass accumulation in $\boldsymbol{S}$. amazonicum seedlings.

\begin{tabular}{|c|c|c|c|c|}
\hline \multirow[b]{2}{*}{ Indicativo } & \multirow[b]{2}{*}{ Variáveis } & \multicolumn{2}{|l|}{ Tratamentos } & \multirow[b]{2}{*}{ Água $100^{\circ} \mathrm{C}$} \\
\hline & & Sem escarificação & Lixa & \\
\hline \multirow[t]{2}{*}{$\overline{\text { Vigor }}$} & E (\%) & n.d.* & $97 \pm 2 a^{* *}$ & $62 \pm 3 b$ \\
\hline & IVE & n.d. & $4,36 \pm 0,5$ a & $1,60 \pm 0,28 \mathrm{~b}$ \\
\hline Uniformidade de & PC (\%) & n.d. & $83 \pm 1,9 a$ & $35 \pm 1,9 \mathrm{~b}$ \\
\hline \multirow[t]{4}{*}{$\begin{array}{l}\text { Plântulas } \\
\text { Pac de }\end{array}$} & PI (\%) & n.d. & $14 \pm 2,0 \mathrm{a}$ & $19 \pm 6,6 \mathrm{~b}$ \\
\hline & SG (\%) & n.d. & $0 \pm 0,0 \mathrm{a}$ & $8 \pm 2,3 \mathrm{~b}$ \\
\hline & SNG (\%) & 100 a & $0 \pm 0,0 \mathrm{c}$ & $15 \pm 3,0 \mathrm{~b}$ \\
\hline & SM (\%) & n.d. & $3 \pm 1,9$ a & $23 \pm 4,4 b$ \\
\hline \multirow[t]{6}{*}{ Biomassa } & Folhas (g) & n.d. & $3,58 \pm 0,44 a$ & $1,43 \pm 0,33 b$ \\
\hline & Epicótilo (g) & n.d. & $0,85 \pm 0,07 a$ & $0,20 \pm 0,06 \mathrm{~b}$ \\
\hline & Hipocótilo (g) & n.d. & $2,34 \pm 0,08 \mathrm{a}$ & $0,67 \pm 0,11 b$ \\
\hline & Cotilédone (g) & n.d. & $0,86 \pm 0,07 \mathrm{a}$ & $1,27 \pm 0,13 b$ \\
\hline & Raiz (g) & n.d. & $1,77 \pm 0,12 \mathrm{a}$ & $0,58 \pm 0,14 b$ \\
\hline & Radícula (g) & n.d. & - & $0,04 \pm 0,01$ \\
\hline
\end{tabular}

*n.d. - sementes não germinadas, e por isso os dados não foram determinados;

** Os dados referem-se às médias de quatro repetições ( 25 sementes cada) \pm erro-padrão da média analisadas após 24 dias do semeio. Letras minúsculas diferentes denotam diferenças significativas (Newman-Keuls, $P<0,05$ ) entre médias de uma mesma variável em função dos tratamentos.

por Cruz e Carvalho (2006), inclusive com relação ao tempo de estabilização da germinação para o tratamento de escarificação em lixa, o que justificou a escolha desse intervalo (12 dias) para os testes de germinação e a depleção do endosperma. Ademais, os resultados obtidos demonstraram claramente que esses métodos de escarificação apresentam diferentes eficiências na quebra de dormência de sementes de paricá (FALESI; SANTOS, 1996; ROSA, 2000; CRUZ; CARVALHO, 2006). A escarificação em lixa foi eficiente em promover a quebra de dormência em Dimorphandra mollis (OLIVEIRA et al., 2008), Acacia mearnsii (MARTINS-CORDER et al., 1999) e em Bowdichia virgilioides (SMIDERLE et al., 2003).

Em termos fisiológicos, foi observado que o método de escarificação em lixa promoveu maior vigor das sementes, conforme demonstrado pelo maior IVG obtido nesse tratamento. Dessa forma, sementes mais vigorosas tendem a alcançar maiores taxas de germinação. Em contraste, tratamentos de escarificação em água a $100{ }^{\circ} \mathrm{C} / 2$ min promoveram menor IVG, resultado semelhante àqueles obtidos para sementes de Mimosa caesalpiniaefolia escarificadas em água fervente por 2 min (BRUNO et al., 2001), para sementes de Bauhinia monandra e Bauhinia ungulata escarificadas em água a $80{ }^{\circ} \mathrm{C}$ (ALVES et al., 2000) e para sementes de Peltophorum dubium (PEREZ et al., 1999) e Cassia excelsa (JELLER; PEREZ, 1999) escarificadas em água fervente por 5 e 10 minutos.

Em sementes de Cassia excelsia escarificadas em água fervente por 5 minutos, foram observadas baixas taxas de germinação e baixo IVG paralelos à maior ocorrência de danos às membranas celulares, causando um incremento no extravasamento de eletrólitos e exsudados (JELLER; PEREZ, 1999). A morte das sementes em função da escarificação em água quente foi também observada em Senna siamea após imersão em água a $45{ }^{\circ} \mathrm{C}$, por 72 e 96 h (DUTRA et al., 2007), e em Stylosanthes scabra, em que $100 \%$ das sementes foram consideradas mortas após a escarificação em água fervente por 1 min (ARAÚJO, 2002). Portanto, as diferentes eficiências dos tratamentos de escarificação testados neste experimento poderiam estar relacionadas a possíveis danos celulares em razão da imersão das sementes em água quente. Isto ocasionaria danos às membranas celulares e maior desnaturação das enzimas relacionadas à respiração celular, podendo até ocasionar a morte dos tecidos. Para testar essa hipótese, as sementes de paricá foram submetidas ao teste de tetrazólio, bastante utilizado em outras espécies florestais

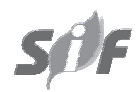

Revista Árvore, Viçosa-MG, v.35, n.4, p.791-800, 2011 
(OLIVEIRA et al., 2005a,b; FERREIRA et al., 2001, 2004; MENDONÇA et al., 2001). O cloreto 2,3,5-trifenil-tetrazólio é um composto químico que, ao reagir com cofatores reduzidos (em especial o NADH) produzidos pelas desidrogenases do Ciclo de Krebs, resulta na formação de um complexo de coloração avermelhada, indicando atividade respiratória e, portanto, tecido vivo (DELOUCHE et al., 1976; BRASIL, 1992). Os resultados obtidos neste trabalho indicaram atividade respiratória independente do método de escarificação utilizado, uma vez que a coloração resultante foi uniforme em todas as estruturas das sementes (endosperma, cotilédones e eixo embrionário). Portanto, as diferenças entre tratamentos de escarificação foram ocasionadas por fatores que não a morte dos tecidos.

Uma vez que os tratamentos de escarificação utilizados nesse experimento não promoveram morte dos tecidos, as diferenças no vigor (IVG) e nas taxas de germinação parecem estar mais relacionadas à eficiência dos métodos de escarificação em promover a embebição das sementes. Isso porque a germinação é completamente dependente da hidratação dos tecidos, o que resulta na retomada do metabolismo. Nesse caso, o método de escarificação em lixa deve ter causado pequenas fragmentações no tegumento da semente, tornando-o mais permeável ao influxo de água durante a embebição e, por essa razão, a curva de embebição para sementes submetidas a esse tratamento indicou a rápida absorção de água pelos tecidos e consequentemente rápida depleção do endosperma. Do contrário, a imersão em água a $100^{\circ} \mathrm{C} / 2 \mathrm{~min}$ pode ter enfraquecido o tegumento por causar uma alteração no número de pontes de hidrogênio formadas entre polissacarídeos de parede, em especial entre microfibrilas de celulose. No entanto, a combinação de temperatura e tempo de imersão utilizado (água $100^{\circ} \mathrm{C} / 2 \mathrm{~min}$ ) foi insuficiente para promover rápida embebição das sementes e rápida depleção do endosperma; e consequentemente baixa taxa de germinação foi registrada para as sementes deste tratamento.

As diferenças na mobilização de reservas em razão das diferentes curvas de embebição em função dos tratamentos de escarificação explicam as diferentes taxas de germinação observadas. Isto porque, com a retomada da hidratação dos tecidos, várias enzimas hidrolíticas são ativadas ou sintetizadas de novo (BEWLEY; BLACK, 1994). Essas enzimas atuam na mobilização de reservas das sementes, que, em leguminosas, ocorrem principalmente na forma de galactomananas e xiloglucanas(BUCKERIDGE, 2000). As galactomananas são cadeias lineares de resíduos de manose unidas por ligações glicosídicas $\beta-(1 \rightarrow 4)$, nas quais resíduos de galactose são inseridos por ligações $\alpha-(1 \rightarrow 6)$ (BUCKERIDGE et al., 2000). As galactomananas ocorrem tipicamente na parede celular das células do endosperma de sementes de leguminosas, mas também estão presentes em sementes de espécies de outras famílias, como Compositae, Convolvulaceae, Annonaceae, Malvaceae, Palmae e Umbelliferae (GUZMÁN; HERNANDEZ, 1982). Em Schizolobium parahyba, um consumo de polissacarídeos (galactomananas e mananas) em diferentes fases da germinação foi observado (PETKOWICZ et al., 2007), de forma que, no sexto dia após a germinação, não foi encontrado resíduo desses polissacarídeos, indicando completa mobilização das galactomananas. Resultados semelhantes foram observados em Sesbania marginata, cuja total degradação de galactomananas foi alcançada no sexto dia de germinação (BUCKERIDGE; DIETRICH, 1996). Comparando-se os resultados supracitados àqueles obtidos neste experimento, é possível inferir, mesmo não tendo determinado os teores de galactomananas, que as reservas contidas no endosperma foram rapidamente mobilizadas em sementes escarificadas em lixa e que esta mobilização influenciou fortemente a alta taxa de germinação das sementes deste tratamento. Para as sementes escarificadas em lixa, as variações observadas nos pesos do endosperma fresco e seco indicaram que este tecido foi completamente exaurido no décimo dia do início da germinação. Do contrário, variações no peso do endosperma em sementes escarificadas em água a $100^{\circ} \mathrm{C} / 2 \mathrm{~min}$ indicaram baixa mobilização de reservas por essas sementes, resultando em menor germinação. A rápida e uniforme germinação das sementes em câmara foi reproduzida em casa de vegetação. Portanto, a escarificação em lixa resultou em maior emergência, IVE e uniformidade de plântulas e mudas, as quais apresentaram maior acúmulo de biomassa em todas as partes.

\section{CONCLUSÕES}

O método de escarificação de sementes de paricá em lixa promove maior germinação das sementes, rápida embebição e depleção do endosperma. Este método permite a produção de plântulas mais uniformes, completas e com maior biomassa que a escarificação das sementes em água a $100^{\circ} \mathrm{C}$. 


\section{AGRADECIMENTOS}

Ao Conselho Nacional de Desenvolvimento Científico e Tecnológico e à Coordenação de Aperfeiçoamento de Pessoal de Nível Superior, pelas bolsas de estudo; ao Projeto CT-Petro Amazônia (PT-01)/ FINEP/Petrobrás.

\section{REFERÊNCIAS}

Alves, M.C.S.; Medeiros-Filho, S.; Andrade-Neto, M. \& Teófilo, E.M. 2000. Superação da dormência em sementes de Bauhinia monandra Britt e Bauhinia ungulata L. - Caesalpinoideae. Revista Brasileira de Sementes 22(2): 139-144.

ARAUJO, E. F. et al. Superação da dureza de sementes e frutos de Stylosanthes scabra J. Vogel e seu efeito na germinação. Revista Brasileira de Sementes, v.24, n.2, p.77-81, 2002.

BARNEBY, R. C. Neotropical Fabales at NY: asides and oversights. Brittonia, v.48, n.2, p.174-187, 1996.

BASKIN, C. C.; BASKIN, J. J. Seeds: ecology, biogeography, and evolution of dormancy and germination. San Diego: Academic Press, 1998. p.101-132.

BEWLEY, J. D.; BLACK, M. Seeds: physiology of development and germination. New York: Plenum Press, 1994. 445p.

BRASIL. Ministério da Agricultura e Reforma Agrária. Regras para análise de sementes. Brasília: SNDA/DNDV/CLAV, 1992. 365p.

BRUNO, R. L. A. et al. Tratamentos pré germinativos para superar a dormência de sementes de Mimosa caesalpiniaefolia Benth. Revista Brasileira de Sementes, v.23, n.2, p.136-143, 2001

BUCKERIDGE, M. S.; DIETRICH, S. M. C. Mobilisation of the raffinose family oligosaccharides and galactomannan in germinating seeds of Sesbania marginata Benth. (Leguminosae-Faboideae). Plant Science, v.117, n.1, p.33-43, 1996.

BUCKERIDGE, M. S. et al. Mobilization of storage cell wall polysaccharides in seeds. Plant Physiology and Biochemistry, v.38, n.1, p.141-156, 2000.
CORDEIRO, I. M. C. C. et al. Indução de calos in vitro de paricá (Schizolobium amazonicum Huber ex Ducke). Plant Cell Culture \& Micropropagation, v.3, n.1, p.35-40, 2007.

CRUZ, E. D.; CARVALHO, J. E. U.; QUEIROZ, R. J. B. Scarification with sulphuric acid of Schizolobium amazonicum Huber ex Ducke seeds - Fabaceae. Scientia Agricola, v.64, n.3, p.308-313, 2007.

CRUZ, E. D.; CARVALHO, J. E. U. Methods of overcoming dormancy in Schizolobium amazonicum Huber ex Ducke (Leguminosae Caesalpinioideae) seeds. Revista Brasileira de Sementes, v.28, n.3, p.108-115, 2006.

CRUZ, E. D.; MARTINS, F. O.; CARVALHO, J. E. U. Biometria de frutos e sementes e germinação de Jatobá-curuba (Hymenaea intermedia Ducke, Leguminosae Caesalpinioideae). Revista Brasileira de Botânica, v.24, n.1, p.161-165, 2001.

DELOUCHE, J. C. et al. O teste de tetrazólio para viabilidade da semente. Brasília: AGIPLAN, 1976. 176p.

DUTRA A. S. et al. Germinação de sementes de Senna siamea (Lam.) H.S. Irwin E Barneby Caesalpinoideae. Revista Brasileira de Sementes, v.29, n.1, p.160-164, 2007.

FALESI, I. C.; SANTOS, J. C. Produção de mudas de paricá - Schizolobium amazonicum Huber ex Ducke. Belém: FCAP, Serviço de Documentação e Informação, 1996. 16p. (Informe Técnico, 20)

FERREIRA, R. A.; DAVIDE, A. C.; MOTTA, M. S. Vigor e viabilidade de sementes de Senna multijuga (Rich.) Irwin et Barn. e Senna macranthera (Collad.) Irwin et Barn., num banco de sementes em solo de viveiro.

Revista Brasileira de Sementes, v.26, n.1, p.24-31, 2004.

FERREIRA, R. A. et al. Morfologia da semente e de plântulas e avaliação da viabilidade da semente de sucupira branca (Pterodon pubescens Benth. - Fabaceae) pelo teste de tetrazólio.

Revista Brasileira de Sementes, v.23, n.1, p.108-115, 2001.

Revista Árvore, Viçosa-MG, v.35, n.4, p.791-800, 2011 
FOWLER, J. A. P.; CARPANEZZI, A. A. Tecnologia de sementes de marica (Mimosa bimucronata (DC) O. Ktze.). Boletim de Pesquisa Florestal, n.36, p.47-56, 1998.

GUZMÁN, J. M.; HERNANDEZ, G. L. Anatomia de la semilla y germinación en la Turbina corumbosa (L.) Raf., Convolvulaceae. Phyton, v. 42, p. 1-8, 1982.

JELLER, H.; PEREZ, S. C. J. G. A. Estudo da superação da dormência e da temperatura em sementes de Cassia excelsa Schrad. Revista Brasileira de

Sementes, v.21, n.1, p.32-40, 1999.

MAGUIRE, J.D. Speed of germination in selection and evaluation of seedling emergence and vigor. Crop Science, Madison, v.2, n.1, p.176-177, 1962.

MARQUES, T. C. L. L. S. M. et al. Crescimento inicial do paricá (Schizolobium amazonicum) sob omissão de nutrientes e de sódio em solução nutritiva. Revista Cerne, v.10, n.2, p.184-195, 2004.

MARTINS-CORDER, M. P. et al. Fotoperiodismo e quebra de dormência em sementes de acácia-negra (Acacia mearnsii Willd.). Ciência Florestal, v.9, n.1, p.71-77, 1999.

MARUYAMA, E.; UGAMOTO, M. Treatments for promoting germination of Parkia oppositifolia Benth. and Schizolobium amazonicum Huber.

Journal of the Japanese Forestry Society, v.71, p.209-211, 1989.

MEDEIROS, A. C. S.; ZANON, A. Superação da dormência e sementes de acáciamarítima (Acacia longifolia). Colombo: Embrapa Florestas, 1999. 12p. (Circular Técnica, 32)

MENDONÇA, E. A. F.; RAMOS, N. P.; PAULA, R. C. Viabilidade de sementes de Cordia trichotoma (Vellozo) Arrabida ex Steudel (louro-pardo) pelo teste de tetrazólio. Revista Brasileira de Sementes, v.23, n.2, p.64-71, 2001.

OLIVEIRA, L. M.; CARVALHO, M. L. M.; DAVIDE, A. C. Teste de tetrazólio para avaliação da qualidade de sementes de Peltophorum dubium (Sprengel) Taubert - leguminosae caesalpinioideae. Revista Cerne, v.11, n.2, p.159-166, 2005a.
OLIVEIRA, L. M.; CARVALHO, M. L. M.; NERY, M. C. Teste de tetrazólio em sementes de Tabebuia serratifolia Vahl Nich. e T. impetiginosa (Martius ex A. P. de Candolle) Standley - Bignoniaceae. Revista Ciência Agronômica, v.36, n.2, p.169-174, 2005b.

OLIVEIRA, D. A. et al. Potencial germinativo de sementes de fava-d'anta (Dimorphandra mollis Benth. - Fabaceae: Mimosoideae) sob diferentes procedências, datas de coleta e tratamentos de escarificação. Revista Árvore, v.32, n.6, p.1001-1009, 2008.

PEREZ, S. C. J. G. A. et al. Dormancy break and light quality effects on seed germination of Peltophorum dubium Taub. Revista Árvore, v.23, n.2, p.131-137, 1999.

PETKOWICZ, C. L. O.; SCHAEFER, S.; REICHER, F. The mannan from Schizolobium parahybae endosperm is not a reserve polysaccharide. Carbohydrate Polymers, v.69, p.659-664, 2007.

RAMOS, M. B. P.; VARELA, V. P.; MELO, M. F. F. Influência da temperatura e da água sobre a germinação de sementes de paricá (Schizolobium amazonicum Huber ex Ducke - LeguminosaeCaesalpinioideae). Revista Brasileira de Sementes, v.28, n.1, p.163-168, 2006.

REIS, I. N. R. S. et al. Indução in vitro de brotos de paricá (Schizolobium parahyba var. amazonicum Huber ex Ducke). Plant Cell Culture \& Micropropagation, v.4, n.1, p.21-27, 2008.

ROSA, L. S.; PINHEIRO, K. A. O. Propagação vegetativa de estacas de paricá (Schizolobium amazonicum Huber ex Ducke) obtidas de material juvenil e imersas em ácido indol-3-butírico. Revista de Ciências Agrárias, v.35, n.1, p.79-88, 2001.

SHIMIZU, E. S. C. et al. Avaliação da viabilidade de sementes de paricá (Schizolobium parahyba var. amazonicum (Huber x Ducker) Barneby) pelo teste de tetrazólio em diferentes concentrações e tempos de resposta. In: CONGRESSO NACIONAL DE BOTÂNICA, 59., 2008. Natal. Anais...Natal: 2008.

SMIDERLE, O. J.; SOUSA, R. C. P. Dormência em sementes de paricarana (Bowdichia virgilioides Kunth- Fabaceae- Papilionidae). Revista Brasileira de Sementes, v.25, n.1, p.72-75, 2003. 